\title{
Investment for sustainable development: panacea, placebo or problematic?
}

\author{
Joyeeta Gupta $\cdot$ Kyla Tienhaara
}

Received: 29 September 2006/ Accepted: 29 September 2006/

Published online: 22 November 2006

(C) Springer Science+Business Media B.V. 2006

While multilateral environmental agreements aim to promote sustainable development, the more recent and less publicised development of numerous bilateral, regional and sectoral investment agreements aims primarily to protect the interests of foreign investors. Do these agreements lead to a conflict between the goals of sustainable development on the one hand, and the desire to promote and protect investment on the other hand? Can such a conflict be resolved? This special issue attempts to deal with these complex issues by first discussing the investment regime and then by looking more closely at the role of foreign investment in the areas of minerals, energy and water especially in, but not necessarily limited to, developing countries.

The history of foreign investment can be traced back some 400 years. While foreign investment historically aimed to benefit primarily the investors, economic theory argues that it also has a critical role to play in promoting development. It is now often suggested that without foreign direct investment the poorer countries in the world will not be in a position to access the finances and technologies needed to accelerate their economic growth. Theoretical discussions of foreign investment have evolved in time from mercantilism, through dependencia to social capital theories; discussions of aid have evolved from the need to invest in infrastructure and big government to the need to invest in good governance; discussions of technology transfer have moved from infant protection, through leap frog theories to appropriate technologies; and these theoretical discussions have not yet come to rest.

In 1992, at the United Nations Conference on Environment and Development in Rio de Janeiro it was stated that huge financial resources would be needed annually to deal with the key development and environmental problems of the developing world. In 2002, at the Johannesburg Earth Summit, one hundred Heads of State and Government acknowledged that "significant increases in investment flows around the world have opened new challenges and opportunities for the pursuit of

J. Gupta $\cdot$ K. Tienhaara $(\bowtie)$

Environmental Policy Analysis, Insitute For Environmental Studies, Vrije Universiteit Amsterdam, De Boelelaan 1087, Amsterdam 1081 HV, The Netherlands

e-mail: kyla.tienhaara@ivm.falw.vu.nl 
sustainable development" (Johannesburg Declaration 2002, Para 14). However, while the Plan of Implementation developed at the Summit is riddled with statements emphasizing the need for countries to promote foreign investment and to create "investment-friendly" environments, the "new challenges" were largely neglected. Absent was any discussion of whether there might be negative implications for sustainable development of increased foreign investment flows in certain sectors, whether there might be interaction between policies at the international and national levels designed to protect investors and those aimed at protecting the environment or promoting social goals, or critically, whether there might be more constructive ways of promoting sustainable flows of investment.

It is these questions that were the recent focus of the work of Konrad von Moltke and the International Institute for Sustainable Development (IISD). Konrad, a member of the editorial board of this journal, had worked on issues of trade and environment for many years, and recognized early on the link between investment and the environment. Much of his work culminated in a proposal by the IISD in 2005 for a Model International Agreement on Investment for Sustainable Development ${ }^{1}$. Sadly, Konrad passed away in May of the same year.

In January 2006, the Institute for Environmental Studies, Vrije Universiteit Amsterdam and the UNESCO-IHE Institute for Water Education, Delft organised an international seminar in Amsterdam, inspired by and dedicated to the memory of Konrad and financed by the Royal Netherlands Academy of Arts and Sciences as well as the Netherlands Organization for Scientific Research. The meeting brought together scholars from a variety of perspectives and disciplines to discuss issues of environment, development, and foreign investment. The papers included in this special issue were amongst the best that materialized from that meeting. As the issues are highly controversial we have solicited several commentaries on the papers from distinguished scientists from all over the world in the hope of providing an even broader perspective on the issues that emerge from each author's work and with the aim of prompting debate amongst scholars.

Investment and sustainable development are concepts with many dimensions. They have complex legal, economic, political and technological aspects. This calls for a multi-disciplinary approach to understanding the issues. While the economic, political and technological dimensions are often discussed, the complex legal issues that are often not discussed in public and are not generally known. This special issue attempts to remedy that particular problem.

We begin thus with a review of the evolution of the international law of foreign investment and the implications that it has for developing countries. Prof. M. Sornarajah of the National University of Singapore, a legal expert and well-known publicist in the field, submits that, in the 1990s, the rise of neo-liberalism led to calls for consolidation of the law of foreign investment primarily to protect the interests of foreign investors. While initial efforts to negotiate such a law in a multilateral forum failed because of the diverse interests of states, ultimately more than 2300 bilateral agreements with similar provisions aimed primarily at protecting the interests of investors have been negotiated between countries. Several arbitration cases arising from disputes between investors (often multinationals) and host countries have led to the establishment of precedents that further protect the interests of investors. A review of the key historical issues leads Sornarajah to

\footnotetext{
${ }^{1}$ Available online at http://www.iisd.org/publications/pub.aspx?id=685

算 Springer
} 
conclude that the law of foreign investment is more a law to protect greed than one to deal with issues of need such as poverty alleviation and environmental protection. He concludes, however, that the seeds of reform are inherent in the evolution of the system and that the current injustices cannot continue indefinitely.

In his reaction, Dr. Howard Mann, an attorney and the lead author of the IISD's Model Agreement, advises the reader to pierce through the "rhetorical flourishes" of Sornarajah's writing and to try and understand why he is disenchanted with international investment law and its impact on poverty and sustainable development, especially as Sornarajah was previously a proponent of investment law. Mann agrees with Sornarajah's critique of the skewed nature of the provisions in bilateral investment treaties, the small group of arbitrators that implicitly control the dispute resolution process, and the lack of transparency and respect for the conditions under which developing countries function. However, he is not quite as sombre about the future and disputes some of the observations made by Sornarajah.

Prof. A. F. M. Maniruzzaman, a professor of International and Business Law and Director of Legal Research at the University of Portsmouth, UK, also comments on Sornarajah's paper. He echoes Sornarajah's concerns that in the present period "international law has seemingly lost its direction and often the sense of its purpose". While he cautions that the call for a law based on need "is not free from controversy" and reminds the reader that multinational corporations are in host states "to do business and not for charity", he strongly agrees that a more "balanced and just international law of foreign investment needs to be developed". Finally, he shares with Sornarajah the view that, while far from perfect, the IISD Model Agreement is a positive first step in the right direction.

Following this general overview of the impacts of the international investment law on development and environmental issues especially in the developing countries, there are three papers focusing specifically on three natural resources - minerals, water, and energy.

Investments in minerals have a long and chequered history. Much of the foreign investment in the mining sector led developing countries to argue in favour of the principle of Permanent Sovereignty over Natural Resources. However, in the more recent context, with many countries competing to attract mineral investment, investors have negotiated specific clauses into their contracts to protect their investments. Such clauses aim, inter alia, to pre-empt states from changing the conditions under which the investors operate as a result of the adoption of new environmental and developmental laws (e.g. the so-called stability clauses). In order to protect themselves from possible adverse contextual changes these investors may resort to, or threaten to resort to, expensive and secretive arbitration and use this as pressure on governments of poor countries. Kyla Tienhaara, a Ph.D. fellow at the Institute for Environmental Studies, Vrije Universiteit Amsterdam, The Netherlands, demonstrates some of these current-day problems through her empirical case study on investment in the minerals sector in Ghana.

In her comment, Lyuba Zarsky of the Global Development and Environment Institute at Tufts University, USA, argues that there is a double governance gap namely the lack of regulation in developing countries and the lack of global rules to regulate industry. She argues that in theory the stability clauses referred to by Tienhaara should not freeze regulation, but instead ensure transparent and careful political processes that lead to changed rules. However, in practice, the outcomes may be different; and she submits that unless contracts and agreements put pressure 
on investors to adopt commitments to the local population, commitments of a social and environmental nature, there may be limited benefits for sustainable development.

Dr. Elizabeth Bastida, the Director of the International Mining Programme at the Centre for Energy, Petroleum and Mineral Law \& Policy at the University of Dundee, UK, argues in her commentary that while mining has the potential to contribute to sustainable development, the current investment law environment is not necessarily conducive to this goal. She focuses in particular on the 'Latin American Mining Law Model', which has been employed as a best-practice guide in the reform of mining law in many developing countries. While the model "has been fully responsive to the needs of the investor", Dr. Bastida argues that it has clear shortcomings in the context of a sustainable development. She concludes that there "is a need to re-examine the premises of the legal and institutional paradigm of the minerals sector-predominant in developing countries-with a view to fully integrate environmental and social considerations into investment decisions" and sites potential alternatives to the Latin American model which can be found in the provisions of mineral regimes in Manitoba (Canada), Colombia, and South Africa.

The next paper looks at the issue of water. The global trends in the water sector show the substantial problems of access to water and sanitation services on the one hand, and the deterioration in water quality worldwide on the other. This clearly calls for huge investment in the sector, yet the required funds are not forthcoming from the public sector, especially in the developing world. This situation led, in the 1990 s, to the call for foreign investment and public private partnerships in the water sector. Fifteen years on, Marco Schouten and Klaas Schwartz, from the UNESCOIHE Institute for Water Education in Delft, The Netherlands, submit that experiences in the sector show that water is unlike most other resources. Without denying the need for investment in the sector, they submit that water is a political good in that ultimately politicians will be held accountable for the water services in their country. As such, contractual arrangements with foreign investors are likely to be breached for either legitimate or political reasons. They submit that this particular aspect of the resource needs to be taken into account before making prescriptions about how to enhance foreign investment in the sector. Meanwhile, the experiences in this sector are leading to less and less resources being invested in the sector and the key problems remain unaddressed.

Prof. Hans Opschoor, former rector of the Institute of Social Studies in The Hague, suggests in his comment that the recognition that water is an economic good does not of itself imply that managing water can be left solely to market forces. He submits that the notion of water as a "political good" is not necessary for analytical or descriptive purposes. Nevertheless the description may be useful for advocacy purposes to draw attention to the complexities of investing in the water sector.

In her reaction, Prof. Helen Ingram of the University of California, Irvine, USA, contends that while she agrees with the diagnosis of the problem, Schouten and Schwartz do not go far enough in their critique. She argues that while the issue of politics is critical, and perhaps a key step for economists, in fact their paper more accurately illustrates the need for open and transparent decision-making in governance processes within countries to ensure that developmental and environmental goals are finally met.

This brings us, finally, to a discussion of energy investments. Energy as a driver for economic development has been the subject of international financial cooperation 
for the last half century. However, increasingly there has been recognition of the kinds of negative side effects of many of these energy sources. While large hydropower projects brought intense scrutiny on foreign investments, the more recent international climate change agreements also raise serious environmental and social questions regarding investments in fossils fuels. In his paper on current issues in energy investment, James Chalker, an American attorney, looks at one particular investment agreement - the Energy Charter Treaty - and analyses how it could be made more "sustainable development friendly". In particular, he focuses on how the dispute settlement system can be reformed to allow for special and differential treatment for developing countries.

His paper provokes Prof. Thomas Wälde of the Centre for Energy, Petroleum and Mineral Law and Policy, at the University of Dundee, UK, to come with a sharp response. He argues that, while we are all motivated by "feel good" approaches, the world is far more complex and the reality is that many investors operate within poorly functioning countries with even poorer legal systems. They are subject to the vagaries and corrupt practices of the politicians in those countries and that makes them extremely vulnerable. Thus there is a need to protect foreign investment and, in the pursuit of the rule of law and good governance, we need to ensure the further development of investment arbitration. Wälde advises against the sentimental and well-meaning efforts of researchers and activists that do not account for the reality of the situation on the ground.

We believe that this special issue on sustainable development and investment illustrates that there is a clear need for sustainable investment in natural resources, particularly in the developing world. However, it appears that the current framework for promoting international investment has not been designed with such a goal in mind. The authors in this special issue understand that investing in a developing country can be a complicated and risky endeavour and that investors should be privy to certain protections. Their papers generally reflect, however, a concern that the current system is weighed too heavily in favour of investor rights. While our authors have used theoretical and empirical arguments to illustrate this concern, our commentators have brought balance by arguing that this is only a part of the problem.

The other side of the problem is the lack of strong and predictable regulatory and legal frameworks in developing countries - the governance gap. The question then, which has been raised though certainly not definitively answered, is whether an international investment regime that develops from a multitude of bilateral and regional agreements and arbitration awards will compensate for the lack of "good governance" at the national level and thereby can be developed more effectively in the short-term to promote sustainable development; or whether there is actually competition between the complex, and often not-transparent, investment regime and the global environmental and developmental regime. We conclude that this question is one that deserves far more attention, and we hope that this special issue may spark interest in researchers to delve into this area more in the years to come.

Acknowledgements The editors gratefully acknowledge the Royal Netherlands Academy of Arts and Sciences for sponsoring the international workshop and the Netherlands Organization for Scientific Research, grant number 452-02-031, for financing some of the research work as part of the project: "Inter-governmental and private environmental regimes and compatibility with good governance, rule of law and sustainable development". 